\title{
Institute of Arctic and Alpine Research
}

\author{
JACK D. IVES*
}

Late in 1967 the University of Colorado went ahead with the first phase of expansion and development of its Institute of Arctic and Alpine Research (INSTAAR). The Institute was founded in 1951 by Dr. John W. Marr who served as its Director until 1967.

The major objective of INSTAAR is the evaluation and appreciation of arctic and alpine environments through research and teaching. The term "environment" is intended to stress the need for an inter-disciplinary philosophy and approach to research, and to teaching through research, at various levels. The underlying principle is the conviction that an adequate understanding of any environment requires a "total" approach, an appreciation of the whole through an integrated study of the parts and of the interrelations between those parts. INSTAAR's particular role is the study of some of the earth's more extreme environments that are found at high altitudes and high latitudes or that existed during glacial phases of the Quaternary Era. As the Institute is going through a phase of major expansion, current emphasis is being placed on the so-called field sciences (earth, biological and atmospheric); the study of man's present and past use of and appreciation of these extreme environments will be added to the program in the near future.

Besides laboratory and office facilities in Boulder, INSTAAR possesses a wellequipped Mountain Research Station at 9,600 feet elevation in the Front Range of the Colorado Rocky Mountains. This provides year-round accommodation and logistical support to altitudes over 12,000 feet within 90 minutes' travel time of the Boulder campus headquarters.

INSTAAR, therefore, is an inter-disciplinary research and teaching organization within the Graduate School. The faculty, while salaried directly through the Institute, hold their professional appointments in the relevant academic department, usually in the College of Arts and Sciences. Their research activities are related to the Graduate School while their teaching responsibilities are coordinated with the relevant department, although special inter-disciplinary courses are developed by the Institute and cross-listed for academic credit currently in Biology, Geography and Geology. In addition to the full-time faculty, INSTAAR staff includes field and laboratory technicians, editorial, secretarial and administrative personnel. Faculty of other departments interested in the Institute's program cooperate as INSTAAR Research Associates.

Graduate students interested in the work of the Institute apply for graduate status within the academic department most closely associated with their proposed

*Director of INSTAAR, University of Colorado, Boulder, U.S.A. 
thesis topic, and obtain financial support through the normal University channels, although the Institute does administer one teaching assistantship valued at $\$ 2,650$ for the academic year together with a waiver of tuition fees.

\section{RESEARCH ACTIVITIES}

During 1968, extensive reconnaissance was undertaken, particularly in the Front Range of the Colorado Rocky Mountains as the first step in establishing a series of long-range, interrelated research programs. These include glaciology, hydrology, climatology, Pleistocene geology, permafrost, archaeology, geomorphology, botany and zoology. Weather stations, apparatus for precise measurement of ground surface heave, and thermoelectric elements as the first phase of permafrost research, have been installed. Several graduate students are already working on various phases of the program to provide material for their graduate dissertations. As back-up, the Mountain Research Station facilities are being expanded, former "summer" buildings are being winterized and a fleet of oversnow vehicles is being built up.

Interrelated with the summer research activities in the Front Range, INSTAAR operates three research participation programs sponsored by the National Science Foundation. These programs provide research experience for twelve high-ability high school boys and girls, eight university undergraduates and five junior college teachers. The participants work closely with INSTAAR faculty on the various on-going research programs.

Research areas outside Colorado include the Canadian Arctic and Alaska. In 1968 two small expeditions, investigating late-glacial chronology and isostatic rebound, were supported in eastern Baffin Island. This summer expeditions will be to Ellesmere Island and Baffin Island. Late-glacial chronology and isostatic rebound will be studied in both areas, while the Baffin Island group will also include reconnaissance of terrestrial and marine arctic biology.

\section{PUBLICATIONS}

The Institute this year began to publish a quarterly scientific journal entitled "Arctic and Alpine Research". The annual subscription to the journal is $\$ 12.00$; papers are solicited from all those who are involved in some aspect of arctic and alpine research or related topics. The first issue was released in February, 1969.

\section{OTHER FACILITIES}

The campus headquarters were housed in the Armory Building, but plans for a move to the upper floor of a modern research building on the east campus are in progress. This will provide the Institute with over 20,000 square feet of prime building space in an attractive, air-conditioned building, containing faculty, staff and student offices, seminar rooms, library and extensive laboratory space. In particular, this accommodation will enable rapid development of 
palynology, geomorphology, soils and climatology laboratories, both for research and graduate teaching.

\section{FACULTY}

Currently there are ten faculty members including a visiting professor who is Director of the Institute of Palynology, Belgium. The others are graduates of Universities in Canada, the United Kingdom, Australia and the U.S.A. In addition there are six Research Associates two of whom are graduates of the University of Lund, Sweden. Twelve eminent U.S. and Canadian scientists compose the INSTAAR Advisory Committee. 